\title{
Transient downregulation of protein $O-N$-acetylglucosaminylation by treatment of high-dose nicotinamide in human cells
}

\author{
Hyung II Lee ${ }^{1}$, Hwa Jeong Cho ${ }^{1}$, Jung A Han ${ }^{1}$, \\ So-Young Jang ${ }^{1}$, Kyoung Min Wang ${ }^{1}$, \\ Hyun Tae Kang ${ }^{1}$ and Eun Seong Hwang ${ }^{1,2}$ \\ ${ }^{1}$ Department of Life Science \\ University of Seoul \\ Seoul 130-743, Korea \\ ${ }^{2}$ Corresponding author: Tel, 82-2-2210-2608; \\ Fax, 82-2-2210-2888; E-mail, eshwang@uos.ac.kr
}

Accepted 19 February 2008

Abbreviations: ALLN, N-acetyl-L-leucinal-L-leucinal-L-norleucinal; GIcNAcylation, N-acetylglucosaminylation; HDAC, histon deacetyltrasferase; IQ, 1,5-dihydroxyquinoline; PARP-1, poly(ADP-ribose) polymerase 1

\begin{abstract}
Nicotinamide at millimolar concentrations affects cell survival in various conditions, and is being utilized therapeutically in many human diseases. However, the effect of an acute treatment of nicotinamide at such high dose on gene expression and cellular metabolism has rarely been determined previously. In this study, we found that levels of $\mathrm{O}-\mathrm{N}$-acetylglucosamin $(\mathrm{O}$ GIcNAc)ylated proteins including Sp1 acutely decreased upon treatment of $10 \mathrm{mM}$ nicotinamide. Concomitantly, Sp1 protein level decreased rapidly through accelerated proteasome-mediated proteolysis. Cotreatment of glucosamine or 2-deoxyglucose, which inhibits protein deGIcNAcylation, effectively blocked the decrease induced by nicotinamide. Interestingly, the decline in the levels of Sp1 and protein 0 GIcNAcylation was only transient lasting for two days post treatment, and this pattern matched closely the rapid fluctuation of the cellular [NAD ]. Our results suggest a possible link between cellular nicotinamide metabolism and protein O-GIcNAcylation, and an existence of cellular [NAD $]$ homeostasis.
\end{abstract}

Keywords: acetylglucosamine; cyclin-dependent kinase inhibitor p21; glycosylation; NAD; nicotinamide; SIR1 protein, human; Sp1 transcription factor

\section{Introduction}

Nicotinamide, a derivative of vitamin B3, is converted to $\mathrm{NAD}^{+}$through the salvage pathway once taken up in cells (Liu et al., 1982). Administration of nicotinamide positively affects survival of a variety of cell types (Li et al., 2004). Recent studies suggest promising therapeutic effect of nicotinamide in a wide variety of models of human diseases such as inflammatory vulgaris, diabetics, psoriasis, and bullous pemphigoid (Li et al., 2004). It also protects brain cells from oxidative damage caused by reperfusion after ischemic infarction (Mokudai et al., 2000), and neuronal and vascular cells against nitric oxide, anoxia, trauma, endotoxic shock, or oxygen/glucose deprivation (Maiese and Chong, 2003). Application of nicotinamide as a possible therapeutic for human diseases requires a thorough understanding on myriad of its effects and action mechanisms at molecular and cellular levels. However, underlying mechanisms for most of the reported effects of nicotinamide appear to be more complicated than initially presumed, and have rarely been clarified. For example, protection of cells from oxidative stress during reperfusion has been believed to be attributed to the nicotinamide-driven supply of $\mathrm{NAD}^{+}$which would be otherwise depleted by heavy poly(ADP-ribosyl)ation of nuclear proteins by PARP-1 (Mokudai et al, 2000). However, recent studies indicate that nicotinamide at high doses might exert cytoprotective effect in ways independent of $\mathrm{NAD}^{+}$supply. It directly inhibits PARP-1 (Virag and Szabo, 2002) and activates Akt (Chong et al., 2004) and thereby may prevent FOXO3a-mediated apoptosis (Skurk et al., 2004). It also has been reported to prevent cell death by directly modulating mitochondrial membrane potential and downregulating caspase- 8, caspase-1 and caspase-3 activities (Kolb and Burkart, 1999).

Nicotinamide also inhibits the activity of SIRT1, an $\mathrm{NAD}^{+}$-dependent histone deacetylase (HDAC) (Luo et al., 2001) responsible for deacetylation of p53 (Vaziri et al., 2001), FOXO proteins (Brunet et al., 2004), and PGC-1 (Rodgers et al., 2005), and thereby affects cellular stress response and metabolism. Furthermore, nicotinamide treatment has been reported to induce GAPDH and glucose-6posphate dehydrogenase possibly through upregulation of cellular $\mathrm{NAD}^{+}$level (Yan et al., 1999). 
These findings suggest that nicotinamide may affect glucose metabolism.

Protein O-GIcNAcylation is a modification by a single $\mathrm{N}$-acetylglucosamine at serine or threonine residues in a variety of proteins including nuclear pore complex proteins, cytoskeletal proteins, and transcription factors such as Sp1 (Hart, 1997). UDP-GIcNAc, the substrate of O-GlcNAcylation, is synthesized de novo from glucose via the hexosamine biosynthetic pathway. Therefore, protein $\mathrm{O}$ glycosylation level may be affected by cellular glucose utilization and possibly be modulated by cellular $\mathrm{NAD}^{+}$level.

In a previous study, we found that nicotinamide treatment causes a decrease in p21WAF1 expression (Kang et al., 2006). We report here that this attenuation of p21WAF1 expression was at least in part due to nicotinamide-mediated downregulation of $\mathrm{Sp} 1$ at protein level. In the nicotinamide-treated cells, O-GIcNAylation of cellular proteins including Sp1 was transiently reduced. Concomitant changes in the levels of protein $\mathrm{O}$ GlcNAcylation and cellular $\left[\mathrm{NAD}^{+}\right]$suggests a possible link between protein O-GlcNAcylation and cellular $\mathrm{NAD}^{+}$or nicotinamide metabolism.

\section{Materials and Methods}

\section{Chemicals and cell culture}

$\mathrm{N}$-acetyl-L-leucinal-L-leucinal-L-norleucinal (ALLN), nicotinamide, SB600125, and 2-deoxyglucose were purchased from Sigma Chemical Co (St. Louis, MO). NIH-H460 cells were purchased from ATCC, and maintained in DMEM containing 10\% FBS (Biowhitaker, Walkersville, MD). Normal human fibroblasts explanted from a new-born foreskin was provided by Dr. Sang Chul Park (Seoul Nat'l University, Korea).

\section{Western blotting analysis}

Cells were lysed in RIPA buffer $(50 \mathrm{mM}$ Tris- $\mathrm{HCl}$, $\mathrm{pH} 7.5,150 \mathrm{mM} \mathrm{NaCl}, 1 \%$ Nonidet P-40, 0.5\% sodium deoxycholate, $0.1 \%$ SDS) containing a protease-inhibitor cocktail (Sigma). 10 or $20 \mu \mathrm{g}$ protein was applied to Western blotting using antibodies to either p21WAF1 (C-19, HRP; Calbiochem, La Jolla, CA), ERK 1/2(K-23), and Sp1 (Santa Cruz Biotechnology, Santa Cruz, CA), and $O$-GlcNAc residue in O-GlcNAcylated proteins (RL2; Affinity BioReagents, Golden, $\mathrm{CO}$ ).

\section{RT-PCR}

Total RNA was isolated using TRIzol reagent (In- vitrogen, Carlsbad, CA) following the manufacturer's protocol. A total of $5 \mu \mathrm{g}$ RNA was converted to cDNA by using MuLV reverse transcriptase and oligo(dT) primer (Promega, Madison, $\mathrm{WI}$ ), and 1/40 volume of the cDNA reaction was applied to PCR using primers for Sp1, IGF-1, and $\beta$-actin. The primer sequences will be provided upon request.

\section{Measurement of total [NAD ] and [NADH]}

To determine cellular $\mathrm{NAD}^{+}$content, a previously published protocol was used (Wosikowski et al., 2002). Briefly, $1 \times 10^{6}$ cells were lysed by adding $200 \mu \mathrm{l}$ cold $\mathrm{HClO}_{4}$ solution $(0.5 \mathrm{M})$. After 15 min on ice, the extracts were neutralized by adding $61 \mu \mathrm{l}$ $2 \mathrm{M} \mathrm{KOH} / 0.2 \mathrm{M} \mathrm{K}_{3} \mathrm{PO}_{4}(\mathrm{pH} 7.5)$ and spun at $13,000 \mathrm{~g}$ for $3 \mathrm{~min}$. $10 \mu \mathrm{l}$ of supernatant or $\mathrm{NAD}^{+}$ standard diluents were mixed with $150 \mu \mathrm{l}$ reaction solution, and after incubation for $30 \mathrm{~min}$ at $37^{\circ} \mathrm{C}$, absorbance at $450 \mathrm{~nm}$ was measured. Reaction solution was composed of $16 \mu \mathrm{l}$ WST-1, $70 \mu \mathrm{M}$ 1-methoxy-5methyl-phenazinium methyl sulfate, 20 IU alcohol dehydrogenase (Sigma), $0.32 \mathrm{M}$ ethanol in $64 \mathrm{mM}$ Gly-Gly buffer ( $\mathrm{pH}$ 7.4). To determine cellular NADH content, cells were lysed in $200 \mu \mathrm{l}$ $0.02 \mathrm{~N} \mathrm{NaOH}$ solution containing $0.5 \mathrm{mM} \mathrm{L}-$ cysteine for $10 \mathrm{~min}$ at $60^{\circ} \mathrm{C}$. $30 \mu \mathrm{l}$ of the neutralized extract or NADH standard diluents was incubated with $130 \mu \mathrm{l}$ reaction solution for $60 \mathrm{~min}$ at $37^{\circ} \mathrm{C}$, and absorbance at $450 \mathrm{~nm}$ was measured.

\section{Results}

\section{Nicotinamide-induced downregulation of Sp1 activity}

Previously, we have shown that acute treatment of $10 \mathrm{mM}$ nicotinamide downregulates p21WAF1 expression in both normal fibroblasts and cancer cells (Kang et al., 2006) as demonstrated with $\mathrm{H} 460$ cells in this study (Figure 1A). This downregulation of p21WAF1 was independent of p53 since it occurred in SKOV3 cell, a p53-null carcinoma line (HI Lee, unpublished data). Since the background level expression of $p 21 W A F 1$ is maintained by Sp1 (Biggs et al., 1996), we checked the level of Sp1 expression (Figure 1A). Indeed, Sp1 protein level got lower upon the treatment of $10 \mathrm{mM}$ nicotinamide. And, the expression of IGF-1 receptor, an Sp1-dependent gene, was also suppressed suggesting that $\mathrm{Sp} 1$ was functionally downregulated by the treatment. The status of the Sp1 protein level was further checked in a time course study for $72 \mathrm{~h}$ in $\mathrm{H} 460$ cells. Treatment of $10 \mathrm{mM}$ nicoti- 
A

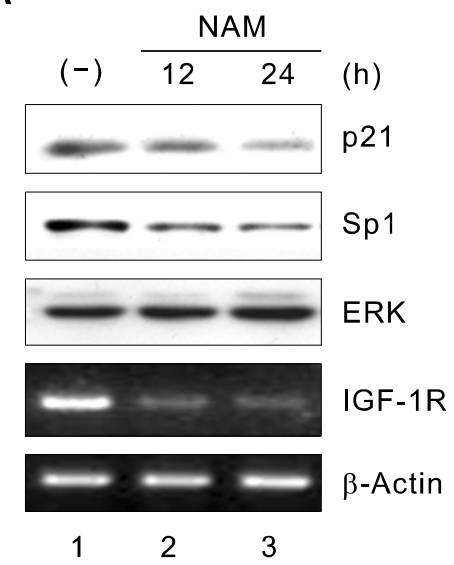

B $\begin{array}{lllllllllll}(-) & 8 & 12 & 16 & 24 & 32 & 40 & 48 & 64 & 72 & \text { (h) }\end{array}$
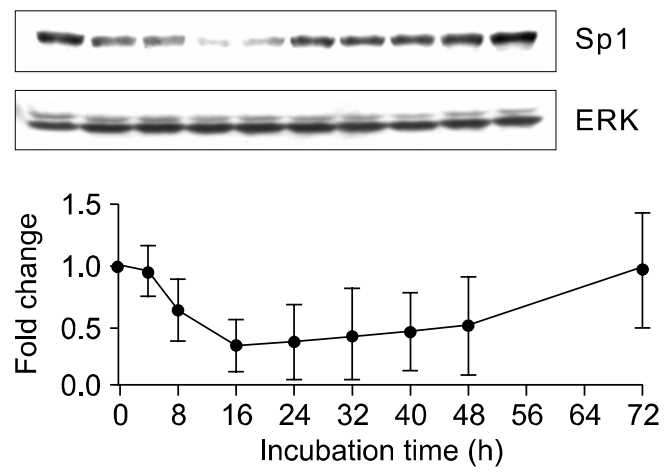

Figure 1. Decreased Sp1 level in cells treated with nicotinamide. (A) H460 cells were treated with 10 $\mathrm{mM}$ nicotinamide for 12 or $24 \mathrm{~h}$, and processed either for Western blotting analysis of p21WAF1, Sp1, and ERK proteins, or for RT-PCR using primers for IGF-1 receptor and $\beta$-actin. (B) Cells treated with $10 \mathrm{mM}$ nicotinamide, collected at the indicated time points, and extracts were applied to Western blotting for Sp1 and ERK proteins. In the graph below, the band intensities relative to that of untreated cells (fold change) were plotted. The values were from 3 independent experiments. (C) Cells were either mock-treated or treated with nicotinamide at the concentration either of 10 or $20 \mathrm{mM}$, collected at the indicated time points, and applied to Western blotting analysis. namide apparently induced a gradual decrease in Sp1 protein level from as early as $8 \mathrm{~h}$ post treatment (Figure 1B). Interestingly, the level reached the lowest point (approximately $30-40 \%$ of the untreated-cell level) in 16-24 h, and thereafter, increased steadily recovering the level of the untreated cells in around $72 \mathrm{~h}$. On average of three independent experiments, Sp1 level was maintained below $50 \%$ from 16 to $48 \mathrm{~h}$ post treatment (Figure 1B, lower panel). The severity of the effect appeared to be dose dependent. While the Sp1 level in the cells treated with $10 \mathrm{mM}$ nicotinamide was restored in $72 \mathrm{~h}$, that in the cells treated with $20 \mathrm{mM}$ nicotinamide was not (Figure 1C). And, addition of $10 \mathrm{mM}$ nicotinamide anew at $24 \mathrm{~h}$ point was unable to prevent the Sp1 level from returning to the background level (JA Han, unpublished result), suggesting that this recovery in Sp1 protein level is not due to a decrease in the supply of nicotinamide. These results together suggest that nicotinamide treatment induces a substantial but transient decrease in the level of Sp1 protein. Sp1 level did not show such fluctuation in $\mathrm{H} 460$ cells cultured in the absence of extra nicotinamide added [Figure 1C (-)].

\section{Accelerated proteolysis of Sp1 in nicotinamide-treated cells}

The level of Sp1 mRNA was not affected by nicotinamide treatment as checked by RT-PCR (Figure 2A) indicating a post-translational mechanism. Sp1 undergoes proteasome-mediated degradation (Han and Kudlow, 1997; Hart, 1997). In fact, when cells were treated with $10 \mathrm{mM}$ nicotinamide together with ALLN, a proteasome inhibitor, Sp1 level did not decrease, and was stably maintained at a level comparable to that of untreated cells (Figure 2B and $\mathrm{C}$ ). The downregulation in p21WAF1 expression by the nicotinamide treatment was also prevented by the presence of ALLN as shown in Figure 2B. These results suggest that the presence of nicotinamide induces a rapid degradation of Sp1 protein through the proteasome system. Previously, it was reported that the proteasome-mediated Sp1 degradation is accelerated in cells under nutritional stress such as glucose starvation where its O-GIcNAcylation of cellular proteins is blocked (Han and Kudlow, 1997; Kudlow and Kennedy, 2006). Therefore, the OGlcNAcylation status of Sp1 was checked. Sp1 protein was immunoprecipitated from the cells treated with $10 \mathrm{mM}$ nicotinamide and then blotted with either anti-Sp1 or anti-O-GIcNAc antibody, $\mathrm{RL}-2$ (Figure 2C), and the intensity of the bands was quantified. The bar graph representing the ratio of the intensities of the RL-2 band over the Sp1 band shows that O-GlcNAcylation level of Sp1 protein got significantly lower upon nicotinamide 
A

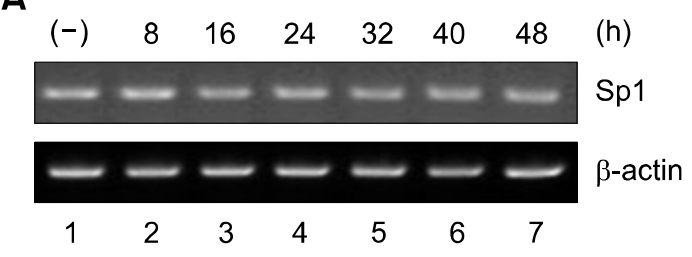

B

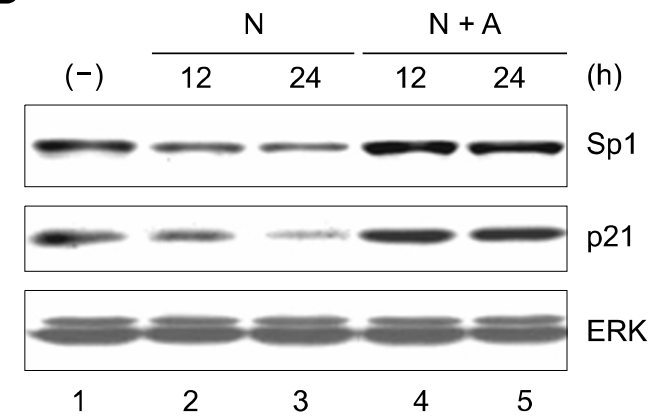

C IP: Sp1
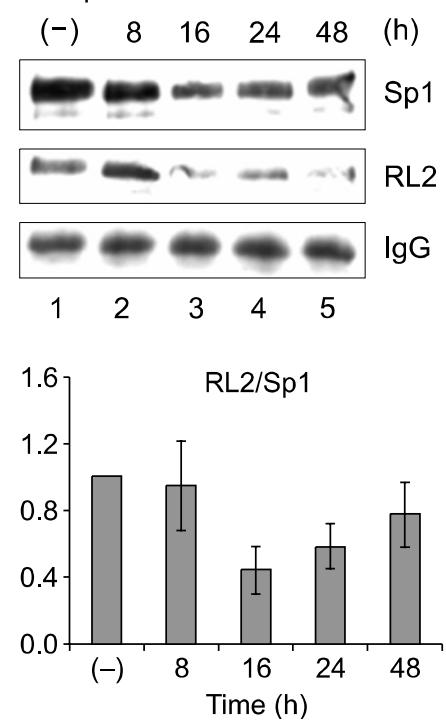

Figure 2. Sp1 downregulation by proteasome-mediated degradation in cells treated with nicotinamide. (A) H460 cells were treated with $10 \mathrm{mM}$ nicotinamide and collected at indicated time points. RNA was isolated and applied to RT-PCR using primers for Sp1 or $\beta$-actin. (B) Cells were treated with $10 \mathrm{mM}$ nicotinamide (N) alone or with $25 \mu \mathrm{M}$ ALLN $(N+A)$ for 12 or $24 \mathrm{~h}$. Cell lysates were applied to Western blotting for Sp1, p21WAF1, and ERK. (C) Cells were treated with $10 \mathrm{mM}$ nicotinamide, collected at the indicated time points, and lysed and applied to immunoprecipitation using the antibody to Sp1. The immunoprecipitates were applied to Western blotting for Sp1, O-GICNAc (RL-2), or murine IgG. In the graph below, the ratio of the intensities of the RL2 band over that of Sp1 band was calculated, and the values normalized by the value from the untreated cells were plotted. The measurements were made from 2 independent experiments.

treatment reaching the lowest point in $16 \mathrm{~h}$, and thereafter, steadily increased.

\section{Nicotinamide-induced downregulation in O-GIcNAcylation of cellular proteins}

Whether O-GIcNAcylation of other cellular proteins as well is affected by nicotinamide treatment was determined by directly blotting total cellular proteins with $R L-2$. The specificity of $R L-2$ to the $O-$ GlcNAcylated proteins in whole cell extract has been demonstrated in a previous study by the increased intensity of the bands from the cells treated with streptozotocin, an inhibitor of $\mathrm{O}$ GlcNAcase (Kang et al., 2003). Upon the treatment of nicotinamide, O-GIcNAcylation level of total cellular proteins was rapidly and dramatically reduced in parallel to the change of Sp1 protein level (Figure 3A). Notably, the treatment of ALLN, a specific inhibitor of proteasome, increased the levels of the RL-2-reactive cellular proteins and Sp1 in both the untreated (lane 4) and the nicotinamide-treated cells (lane 3 ) indicating that the nicotinamide-induced decrease in the levels of the O-GIcNAcylated proteins is due to the increased proteasomal degradation of the poorly O-GIcNA- cylated proteins as is the case with Sp1. The decrease in the level of the O-GlcNAcylated proteins showed a time-course profile that is identical to that of Sp1 (Figure 3B, NAM). Furthermore, the nicotinamide-induced decrease in both the O-GIcNAcylation level of cellular proteins and the Sp1 level was blocked by co-treatment of $10 \mathrm{mM}$ glucosamine, a key precursor and stimulator of protein O-GIcNAcylation (Konrad et al., 2000) or 45 $\mathrm{mM}$ 2-deoxyglucose, a glucose-derivative that has been shown to inhibit protein de-GlcNAcylation (Kang et al., 2003) (Figure 3B, NAM + GA and $\mathrm{NAM}+2-D G)$. This strongly suggests a possibility of a direct interference by nicotinamide in protein O-GIcNAcylation. Previously, Zhang et al. (2003) reported that nutritional stress such as glucose starvation causes poor O-GIcNAcylation of cellular proteins including Rpt2 ATPase, a subunit of proteasome complex, which leads to proteasome activation. Based on this notion, our results suggest a possibility that Sp1 downregulation in nicotinamidetreated cells was caused by proteasome activation through hypo-GlcNAcylation of its Rpt2 ATPase subunit along with other cellular proteins. Meanwhile, both the levels of Sp1 protein and the GlcNAcylated cellular proteins were maintained 
A

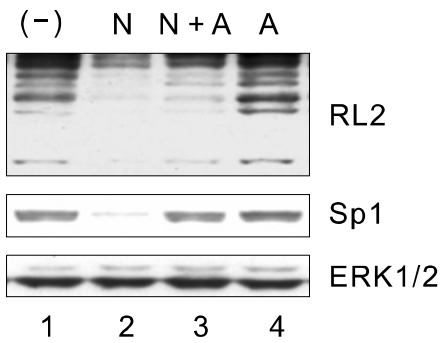

C

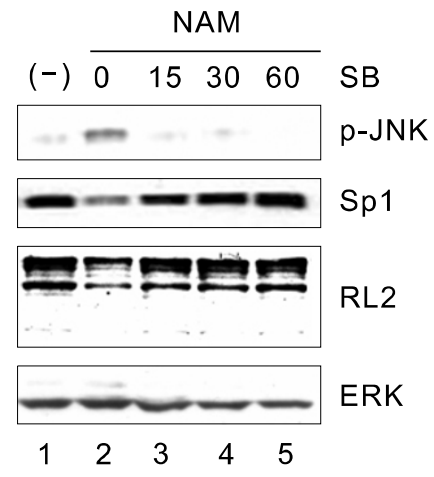

B

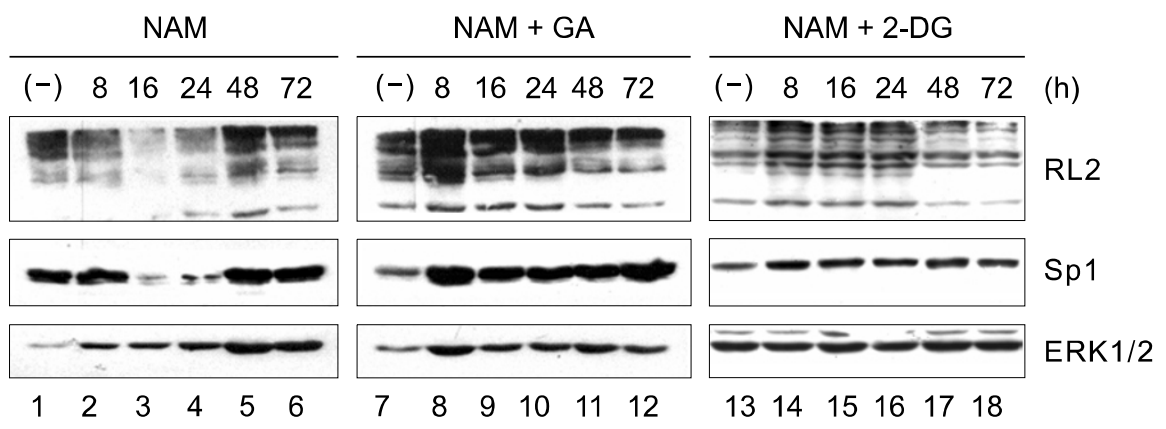

Figure 3. Parallel alterations in the levels of protein 0-GlcNAcylation and $S p 1$ in cells treated with nicotinamide. (A) H460 cells were treated with $10 \mathrm{mM}$ nicotinamide (N)(lane 2), $25 \mu \mathrm{M}$ ALLN (A)(lane 4) alone or together $(\mathrm{N}+\mathrm{A})$ (lane 3). After $24 \mathrm{~h}$, cells were lysed and applied to Western blotting for O-GICNAc (RL-2), Sp1 and ERK. (B) Cells were treated with $10 \mathrm{mM}$ nicotinamide alone (NAM) alone (lanes 2-6), or together with $10 \mathrm{mM}$ glucosamine (NAM + GA)(lanes 712) or $45 \mathrm{mM}$ 2-deoxyglucose (NAM + 2-DG)(lanes 13-18). At indicated time points, cells were collected, and extracts were applied to Western blotting analysis. (C) Cells were treated with $10 \mathrm{mM}$ nicotinamide alone (lane 2), or together with 15,30 , or $60 \mathrm{mM}$ SB600125 (lanes 3,4 , and 5). After $24 \mathrm{~h}$, cells were lysed and applied to Western blotting using phosphorlated JNK (to show effectiveness of SB600125 treatment), RL-2, or antibodies to Sp1 or ERK.
A

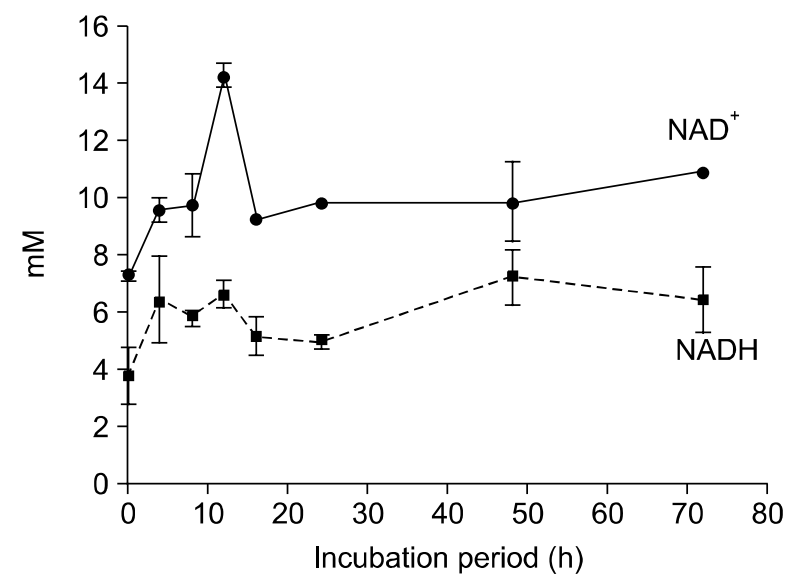

B

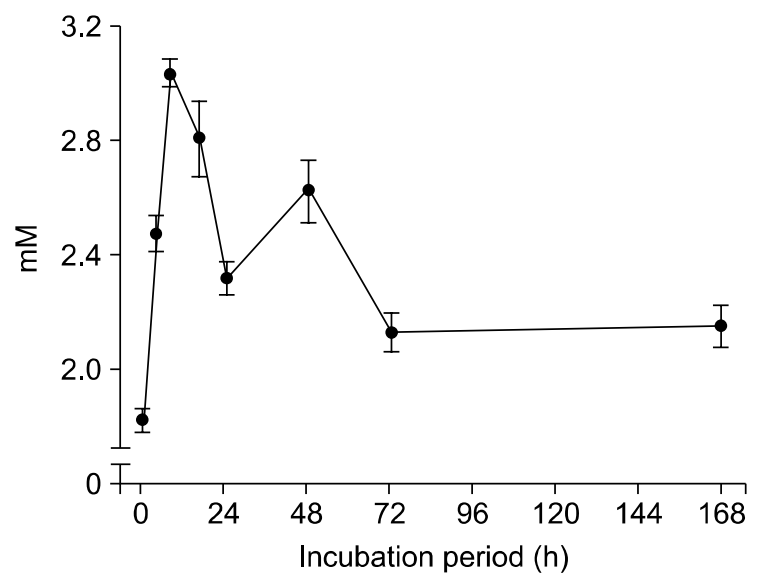

Figure 4. Rapid up and down of total $\mathrm{NAD}^{+}$level in cells treated with nicotinamide. $\mathrm{H} 460$ cells (A) and normal human fibroblasts (B) were treated with 10 $\mathrm{mM}$ nicotinamide. At indicated time points, cells were collected and cellular levels of total NAD+ (-) and NADH (----) were measured. Mean values from the measurement of 3 independent experiments were plotted.

high when cells were co-treated with SB600125, an inhibitor of c-Jun N-terminal kinase (Ventura et al., 2006) (Figure 3C). In this experiment, inhibitors of several kinases involved in various cellular signal transduction pathways were tested in order to determine possible involvement of a signaling pathway. Among the tested, SB600125 substantially blocked the effect of nicotinamide, suggesting an involvement of a JNK-mediated signaling in the effect of nicotinamide. 


\section{Rapid fluctuation of $\mathrm{NAD}^{+}$level upon nicotinamide treatment}

Nicotinamide is converted to $\mathrm{NAD}^{+}$through the salvage pathway (Liu et al., 1982). Therefore, cellular $\left[\mathrm{NAD}^{+}\right.$] level is expected to rise upon the addition of nicotinamide in the culture medium. Indeed, total cellular $\left[\mathrm{NAD}^{+}\right]$increased rapidly approaching near 2-fold level in $12 \mathrm{~h}$ (Figure 4A). However, the level suddenly dropped thereafter, and maintained at levels slightly higher than that of the untreated cells. The reason for this sudden decrease in $\left[\mathrm{NAD}^{+}\right]$is not clear, but not an isolated phenomenon of $\mathrm{H} 460$ cells since this pattern of rapid up and down of cellular $\left[\mathrm{NAD}^{+}\right]$at the early time points of nicotinamide treatment was also found in normal human fibroblasts (Figure 4B). And, it apparently is not due to an increased conversion of $\mathrm{NAD}^{+}$to $\mathrm{NADH}$ since the [NADH] changed in a similar pattern. This change in the $\left[\mathrm{NAD}^{+}\right]$roughly preceded that of the Sp1 protein (Figure 1B) and the decrease in O-GlcNAcylation of total cellular proteins (Figure $3 \mathrm{~B}$ ) suggesting a possibility that this change in $\left[\mathrm{NAD}^{+}\right]$is associated with the alteration in the levels of protein O-GlcNAcylation. This pattern of $\left[\mathrm{NAD}^{+}\right]$change was reproduced in human normal fibroblasts treated with $10 \mathrm{mM}$ nicotinamide (HT Kang, unpublished result).

\section{Discussion}

The results of this study show that nicotinamide treatment induces hypo-GlcNAcylation of cellular proteins including Sp1 and causes proteasomemediated Sp1 degradation. A preliminary result also indicates a possible involvement of the activity of JNK in this effect of nicotinamide, suggesting a cellular event linked to a stress-signaling pathway. Interestingly, the effect of nicotinamide is transient. With some variation in the severity and the duration in the downregulation of Sp1 level, this transient pattern was also observed in MCF-7 and HeLa cells (data not shown). Possibly due to this transient nature, the effect of nicotinamide itself has not been noticed before, and may not play much significant role in experiments and therapeutic applications.

However, what is note-worthy is the possibility that the nicotinamide metabolism is linked to cellular protein modification, and thereby, to their activity. Earlier, it has been noted that Sp1 stability is regulated by the cellular nutrition level through its O-GlcNAcylation, and therefore, Sp1 has been considered a molecule that links cellular nutritional status and gene expression (Jackson and Tjian,
1988). More recently, however, it has been shown that not the status of O-GICNAcylation of Sp1 but that of Rpt2 ATPase subunit is what determines the Sp1 stability in cells under nutritional stress (Zhang et al., 2003). Proteasome with a hypoGlcNAcylated Rpt2 ATPase subunit has high proteasome activity targeting Sp1. Therefore, the decreased level of protein O-GIcNAcylation rather than downregulation of Sp1 may rather be a more profound and direct consequence of the nicotinmaide treatment. And, since an early and transient JNK activation is known to promote cell survival (Ventura et al., 2006), the change imposed in the nicotinamide-treated cells may be a cellular effort to survive under a metabolic stress. The possible role of JNK pathway warrants further investigation.

How does high level nicotinamide cause protein hypo-GlcNAcylation in cells? Protein O-GIcNAcylation is modulated by cellular glucose level (Biggs et al., 1996), and $\mathrm{NAD}^{+}$is a key molecule regulating glucose metabolism. Therefore, nicotinamide, a precursor of $\mathrm{NAD}^{+}$, may link glucose metabolism to protein O-GIcNAcylation. Upon treatment of nicotinamide, $\left[\mathrm{NAD}^{+}\right]$increased quite rapidly reaching a two-fold level in $12 \mathrm{~h}$ in $\mathrm{H}-460$ cells. Note-worthily, the level dropped rapidly, and thereafter, was maintained rather steadily. This pattern of $\left[\mathrm{NAD}^{+}\right]$ change is quite a mirror-image of the changes in the Sp1 level and protein O-GIcNAcylation. Based on these results, a hypothesis may be proposed that an increase in $\left[\mathrm{NAD}^{+}\right]$is recognized as a state of poor cellular glucose level, and therefore, cells limit utilization of glucose for protein O-GIcNAcylation. Couple of sketches as for a possible mechanism can be drawn from previous reports. Treatment of $10 \mathrm{mM}$ nicotinamide (or nicotinic acid) has been shown to upregulate GAPDH in Jurkat cells (Yan et al., 1999). High GAPDH activity may drive consumption of glucose through glycolysis rather than through hexosamine biosynthetic pathway (HBP), which converts fructose-6-phosphate to UDP-N-acetylglucosamine for protein GlcNAcylation (Yki-Jarvinen et al., 1997). Or, high level nicotinamide and $\mathrm{NAD}^{+}$may downregulate $\mathrm{HBP}$ by increasing cellular cAMP level through inhibition of cAMP phosphodiesterase (Shimoyama et al., 1975; Dudkin et al., 1983). cAMP and cAMP-dependent protein kinase (PKA)-mediated phsphorylation have been shown to inhibit glutamine:fructose-6phosphate amidotransferase (GFAT) which produces glucosamine for HBP (Kudlow and Kennedy, 2006). To validate this hypothesis, it needs to be checked if high level nicotinamide indeed causes a decrease in HBP activity.

Why the effect of nicotinamide is transient is another intriguing question. Sp1 downregulation 
and protein GlcNAcylation lasted for 36-72 h. And, as protein hypo-GlcNAcylation/downregulation accompanied the increase in cellular $\left[\mathrm{NAD}^{+}\right]$, their recovery accompanied its decrease, too. If the downregulation was indeed induced by high $\left[\mathrm{NAD}^{+}\right]$as postulated above, the effect would lessen when the cellular [NAD $\left.{ }^{+}\right]$decreases. Again, a question remains why the $\left[\mathrm{NAD}^{+}\right]$declined so rapidly. It is certainly not due to conversion to NADH whose level changed in parallel to that of $\mathrm{NAD}^{+}$. This rapid fluctuation in $\left[\mathrm{NAD}^{+}\right]$was observed in many tested cells upon treatment of nicotinamide (HT Kang, unpublished result). And, such a rapid fluctuation in cellular response is not an isolated case. For example, cellular ROS level has been shown to oscillate upon treatment of high-level glucose (Yu et al., 2006). Maybe, cells counteract the increase in $\left[\mathrm{NAD}^{+}\right]$and rapidly gain its balance for proper energy metabolism. Abrupt increase in $\left[\mathrm{NAD}^{+}\right]$due to exogenous supply would certainly disrupt normal glucose- and energy-metabolism as well as other cellular activities including protein O-GlcNAcylation, and therefore, would destroy cellular normality. Therefore, cells may have developed means to rapidly revert from abnormal $\left[\mathrm{NAD}^{+}\right]$. This may constitute an important cellular homeostasis function that endows cells proper metabolic as well as stress responses.

Overall, despite a transient nature, nicotinamide treatment causes a significant shift in protein $O$ GlcNAcyaltion and thereby the levels of certain cellular proteins. Further investigation on the action mechanism of nicotinamide would shed light on cellular machinery that regulates the balance of glucose/energy metabolism and protein $\mathrm{O}$ GIcNAcyation.

\section{Acknowledgements}

This work was supported by a grant from the Korea Science and Engineering Foundation (KOSEF) (R01-2004000-10803-0).

\section{References}

Biggs JR, Kudlow JE, Kraft AS. The role of the transcription factor Sp1 in regulating the expression of the WAF1/CIP1 gene in U937 leukemic cells. J Biol Chem 1996;271:901-6

Brunet A, Sweeney LB, Sturgill JF, Chua KF, Greer PL, Lin Y, Tran H, Ross SE, Mostoslavsky R, Cohen HY, Hu LS, Cheng HL, Jedrychowski MP, Gygi SP, Sinclair DA, Alt FW, Greenberg ME. Stress-dependent regulation of FOXO transcription factors by the SIRT1 deacetylase. Science 2004;303:2011-5

Chong ZZ, Lin SH, Maiese K. The NAD+ precursor nico- tinamide governs neuronal survival during oxidative stress through protein kinase $\mathrm{B}$ coupled to $\mathrm{FOXO} 3 \mathrm{a}$ and mitochondrial membrane potential. J Cereb Blood Flow Metab 2004;24:728-43

Dudkin SM, Mikchaylova LI, Severin ES Jr. Mechanisms of cyclic AMP phosphodiesterase regulation. Adv Enzyme Regul 1983;21:333-52

Han I, Kudlow JE. Reduced O glycosylation of Sp1 is associated with increased proteasome susceptibility. Mol Cell Biol 1997;17:2550-5

Hart GW. Dynamic O-linked glycosylation of nuclear and cytoskeletal proteins. Annu Rev Biochem 1997;66:315-35

Jackson SP, Tjian R. O-glycosylation of eukaryotic transcription factors: implications for mechanisms of transcriptional regulation. Cell 1988;55:125-33

Kang HT, Ju JW, Cho JW, Hwang ES. Down-regulation of Sp1 activity through modulation of O-glycosylation by treatment with a low glucose mimetic, 2-deoxyglucose. J Biol Chem 2003;278:51223-31

Kang HT, Lee HI, Hwang ES. Nicotinamide extends replicative lifespan of human cells. Aging Cell 2006;5:423-36

Kolb H, Burkart V. Nicotinamide in type 1 diabetes. Mechanism of action revisited. Diabetes Care 1999;22 Suppl 2:B16-20

Konrad RJ, Janowski KM, Kudlow JE. Glucose and streptozotocin stimulate $\mathrm{p} 135 \mathrm{O}$-glycosylation in pancreatic islets. Biochem Biophys Res Commun 2000;267:26-32

Kudlow BA, Kennedy BK. Aging: progeria and the lamin connection. Curr Biol 2006;16:R652-654

Li F, Chong ZZ, Maiese K. Navigating novel mechanisms of cellular plasticity with the NAD+ precursor and nutrient nicotinamide. Front Biosci 2004;9:2500-20

Liu G, Foster J, Manlapaz-Ramos P, Olivera BM. Nucleoside salvage pathway for NAD biosynthesis in Salmonella typhimurium, J Bacteriol 1982;152:1111-6

Luo J, Nikolaev AY, Imai S, Chen D, Su F, Shiloh A, Guarente L, Gu W. Negative control of p53 by Sir2alpha promotes cell survival under stress. Cell 2001;107:137-48

Maiese K, Chong ZZ. Nicotinamide: necessary nutrient emerges as a novel cytoprotectant for the brain. Trends Pharmacol Sci 2003;24:228-32

Mokudai T, Ayoub IA, Sakakibara Y, Lee EJ, Ogilvy CS, Maynard KI. Delayed treatment with nicotinamide (Vitamin $B(3)$ ) improves neurological outcome and reduces infarct volume after transient focal cerebral ischemia in Wistar rats. Stroke 2000;31:1679-85

Rodgers JT, Lerin C, Haas W, Gygi SP, Spiegelman BM, Puigserver P. Nutrient control of glucose homeostasis through a complex of PGC-1alpha and SIRT1. Nature 2005;434:113-8

Shimoyama M, Kawai M, Nasu S, Shioji K, Hoshi Y. Inhibition of adenosine 3',5'-monophosphate phosphodiesterase by nicotinamide and its homologues in vitro. Physiol Chem Phys 1975;7:125-32

Skurk C, Maatz H, Kim HS, Yang J, Abid MR, Aird WC, Walsh 
$\mathrm{K}$. The Akt-regulated forkhead transcription factor FOXO3a controls endothelial cell viability through modulation of the caspase-8 inhibitor FLIP. J Biol Chem 2004;279:1513-25

Vaziri H, Dessain SK, Ng Eaton E, Imai SI, Frye RA, Pandita TK, Guarente L, Weinberg RA. hSIR2(SIRT1) functions as an NAD-dependent p53 deacetylase. Cell 2001;107:149-59

Ventura J, Hubner A, Zhang C, Flavell RA, Shokat KM, Davis RJ. Chemical genetic analysis of the time course of signal transduction by JNK. Mol Cell 2006;21:701-10

Virag L, Szabo C. The therapeutic potential of poly (ADP. ribose) polymerase inhibitors. Pharmacol Rev 2002;54: $375-420$

Wosikowski K, Matterrn K, Schemainda I, Hasmann M, Rattel B, Loser R. WK175, a novel antitumor agent, decrease the intracellular nicotinamide adenine dinucleotide concentration and induces the apoptotic cascade in human leukemia cells. Cancer Res 2002;62:1057-62

Yan Q, Briehl M, Crowley CL, Payne CM, Bernstein H,
Bernstein C. The NAD+ precursors, nicotinic acid and nicotinamide upregulate glyceraldehyde-3-phosphate dehydrogenase and glucose-6-phosphate dehydrogenase mRNA in Jurkat cells. Biochem Biophys Res Commun 1999;255:133-6

Yki-Jarvinen $H$, Vogt $C$, lozzo P, Pipek R, Daniels MC, Virkamaki A, Makimattila S, Mandarino L, DeFronzo RA, McClain D, Gottschalk WK. UDP-N-acetylglucosamine transferase and glutamine: fructose 6-phosphate amidotransferase activities in insulin-sensitive tissues. Diabetologia 1997; 40:76-81

Yu T, Robotham JL, Yoon Y. Increased production of reactive oxygen species in hyperglycemic conditions requires dynamic change of mitochondrial morphology. Proc Natl Acad Sci USA 2006;103: 2653-8

Zhang F, Su K, Yang X, Bowe DB, Paterson AJ, Kudlow JE. O-GICNAc modification is an endogenous inhibitor of the proteasome. Cell 2003;115:715-25 